\title{
Improving PM Collection of EPA Other Test Method (OTM) 36 Precutter
}

\author{
Joshua Udvardy \\ University of Florida
}

Faculty mentor: Chang-Yu We, Department of Environmental Engineering Sciences

\begin{abstract}
The Environmental Protection Agency (EPA) regulates the amount of particulate matter (PM) emitted by different industrial processes to protect human health and the environment. EPA Test Method 5 is the standard method to determine PM emissions from stationary sources. However, moisture present in emission sources can yield overestimated PM concentrations when using EPA Method 5. Alternatively, EPA Other Test Method (OTM) 36 regulates the method used for determining the concentration of PM 2.5 emissions, which are particles with a diameter of less than 2.5 micrometers, from moisture-saturated stationary source gas streams. The EPA has found that the OTM 36 sampling train measures lower PM concentrations than actual concentrations in the emission source. This is because the sampling train's precutter nozzle, which is the first instrument of a sampling train placed into an emission source, collects particles at smaller sizes than intended, preventing these particles from being measured by the sampling train. The purpose of this research is to create a new precutter nozzle design that allows the PM sampling train to more accurately measure PM to reflect actual concentrations in emission sources tested by OTM 36. By using computational fluid dynamics (CFD) simulations in ANSYS Fluent program, the collection efficiency of different dimensions of the new precutter nozzle was calculated to choose the best design that more accurately collects PM. Based on this objective, a precutter nozzle with a $7^{\circ}$ half-cone angle and 3 -cm throat length was chosen as the most viable design.
\end{abstract}

Keywords: air pollution control, particulate matter, computational fluid dynamics

\section{Introduction}

Particulate matter (PM) is defined as solid particles or liquid droplets found in the air, which can range from dust and pollen to metals. To protect human health and the environment, the Environmental Protection Agency (EPA) sets regulations for the amount of PM sources of different industries that is allowed to emit. In order to properly regulate emitting sources, test methods and instruments must be able to accurately measure PM concentrations. EPA Test Method 5 is the standard method to determine PM emissions from stationary sources, such as smoke stacks (Method 5, 1991). However, moisture present in emission sources can yield overestimated PM concentrations when using EPA Method 5 (Garnett, 2015). Alternatively, the proposed EPA Other Test Method (OTM) 36 determines the concentration of $\mathrm{PM}_{2.5}$ emissions, which are particles with a diameter of less than 2.5 micrometers, from moisture-saturated 
stationary source gas streams (Measurement Technology Group, 2016). The EPA has found that the OTM 36 precutter nozzle, which is the first instrument of a sampling train placed into a smoke stack, collects particles at smaller sizes than intended (Williamson et al., 1987). $\mathrm{PM}_{2.5}$ concentrations are determined by OTM 36 by directly measuring the mass of $\mathrm{PM}_{2.5}$ and air flow of a sample. However, $\mathrm{PM}_{2.5}$ only makes up a fraction of total PM in a smoke stack. The purpose of a precutter nozzle is to collect PM of larger diameters that are not a major concern to human health and the environment; the human respiratory system can sufficiently protect itself from larger particles, and the mass of larger particles would cause them to settle out of the air. If a precutter nozzle is not efficient enough at collecting particles, larger particles would be measured by the sampling train, overestimating the $\mathrm{PM}_{2.5}$ concentration. If a precutter nozzle is too efficient, smaller particles that should be measured by the sampling train will instead be collected by the precutter nozzle, underestimating the $\mathrm{PM}_{2.5}$ concentration. In OTM 36, the proposed precutter nozzle not only collects larger particles, but also collects smaller particles that should be measured by the sampling train. As a result, the sampling train measures lower PM concentrations than actual values in the emission source, reducing the viability of OTM 36.

Known as isokinetic sampling, the sampled flow enters the precutter nozzle at the same velocity as the stack velocity. The purpose of isokinetic sampling is to capture the same level of PM concentration through the inlet of a nozzle that would have been present in undisturbed flow (Liu et al., 1989). Sampling at a velocity different than the source velocity would lead to an underestimation or overestimation of the concentration of PM in the source.

Once a sampled flow rate enters the precutter nozzle, the flow is filtered by an impactor to collect larger particles and allow smaller particles to continue further into a sampling train. Before the sampled flow reaches the impactor, because the targeted velocity for impaction is lower than the velocity at the nozzle, the velocity must be decreased to accurately collect the targeted size of particles. The flow velocity can be decreased primarily by increasing the halfcone angle of a nozzle's diffuser and increasing the throat length (see Figures 1 and 2). 


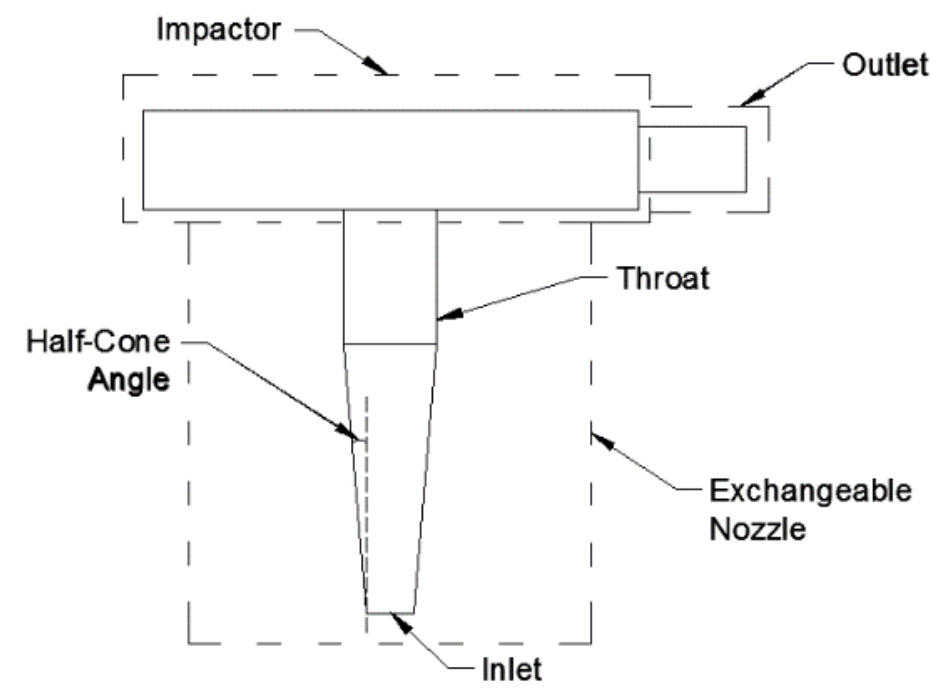

Figure 1: General configuration of a precutter nozzle (side view).

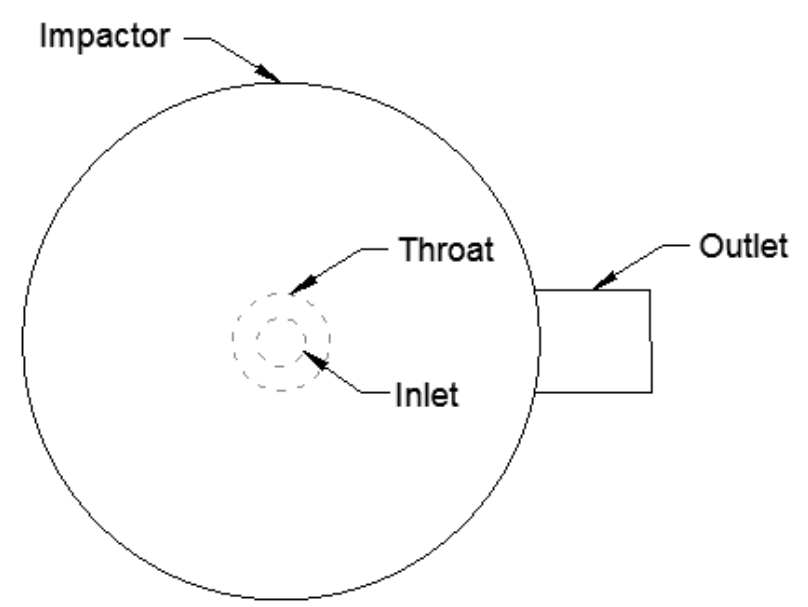

Figure 2: General configuration of a precutter nozzle (top view).

One design limitation of precutter nozzles is the possibility for inverse flow from the halfcone angle becoming too large. Increasing the half-cone angle decreases the velocity on the principle of continuity; if a flow rate remains constant but the cross-sectional area is increased under a constant pressure gradient, the velocity must decrease for the flow rate to remain constant (Murdock, 1993). As the sampled flow is in the direction of an increasing crosssectional area, frictional effects along the walls of the nozzle can lead to flow separation near the walls. If flow separation develops, the pressure gradient within the nozzle can become positive, potentially yielding inverse flow. As inverse flow occurs, the wall boundary cannot effectively drag the main flow, leading to higher particle inertia that inaccurately captures PM. 
One way to avoid inverse flow reaching the impactor is to increase the nozzle's throat length. If the throat of a constant cross-sectional area is long enough, the turbulence from a diffuser's changing cross-sectional area will subside, eliminating inverse flow before air flow reaches the impactor. A limitation to the throat length of a precutter nozzle is the size of the emission source's sampling port. A source's sampling port is where an engineer would insert the precutter nozzle into the source to sample the source's flow. As a standard sampling inlet is usually no larger than $10.16 \mathrm{~cm}$ (4 inches) in diameter, a precutter nozzle larger than this would not be able to fit into a sampling port. Therefore, the overall height of the proposed nozzle is limited to 4 inches (General Compliance Test Requirements, 1998).

The objective of this research was to determine the optimal design dimensions (half-cone angle and throat length) for a precutter nozzle to accurately measure PM that avoids potential inverse flow and fits within the dimensions of a typical source's sampling inlet.

\section{Methods}

\section{Potential Design Configurations}

Design changes targeted a nozzle's half-cone angle and throat length. The scope of designed half-cone angles was narrowed to $3^{\circ}, 5^{\circ}$ and $7^{\circ}$, based upon research of previous studies (see Table 1). Potential throat lengths were $0.96,2,3$ and $3.5 \mathrm{~cm}$, with the maximum throat length determined by the typical dimensions of a stack's sampling inlet (see Table 2).

Table 1. A comparison of half-cone angles of nozzles from previous studies and current research (John et al., 2003).

\begin{tabular}{|c|c|c|c|c|}
\hline Sampler & $\begin{array}{c}\text { Wet Stack Inertial } \\
\text { Droplet Separator } \\
\text { (IDS) (Version 5) }\end{array}$ & $\begin{array}{c}\text { In-stack PM } \\
\text { cyclone (EPA } \\
\text { Method M201a) }\end{array}$ & $\begin{array}{c}\mathrm{PM}_{10} / \mathrm{PM}_{2.5} \text { cascade } \\
\text { impactor (GMU } \\
\text { impactor Johnas) }\end{array}$ & $\begin{array}{c}\text { Precutter Nozzle } \\
\text { (EPA OTM 36) } \\
\text { (Current research) }\end{array}$ \\
\hline Developer & $\begin{array}{c}\text { Baldwin \& Desert } \\
\text { Research Institute, } \\
\text { USA (2012) }\end{array}$ & $\begin{array}{c}\text { Southern Research } \\
\text { Institute, USA } \\
(1987)\end{array}$ & $\begin{array}{c}\text { Gerhard Mercator } \\
\text { University, Germany } \\
(2003)\end{array}$ & $\begin{array}{c}\text { University of } \\
\text { Florida, USA }\end{array}$ \\
\hline $\begin{array}{c}\text { Half-cone angle } \\
\left({ }^{\circ}\right.\end{array}$ & 6 & 3.5 or 7 & 15 & $3,5,7$ \\
\hline
\end{tabular}


Table 2: Dimensions of proposed precutter nozzle designs, with nozzle lengths and total lengths determined by choosing throat lengths and half-cone angles.

\begin{tabular}{|l|c|c|c|c|c|c|}
\hline \multicolumn{1}{|c|}{ Design } & $\mathbf{1}$ & $\mathbf{2}$ & $\mathbf{3}$ & $\mathbf{4}$ & $\mathbf{5}$ & $\mathbf{6}$ \\
\hline Throat Length $(\mathbf{c m})$ & 0.96 & 0.96 & 2 & 3 & 3 & 3.5 \\
\hline Half-Cone Angle $\left({ }^{\circ}\right)$ & 3 & 5 & 5 & 5 & 7 & 7 \\
\hline Nozzle Length $(\mathbf{c m})$ & 6 & 3.34 & 3.34 & 3.34 & 2.37 & 2.37 \\
\hline Total Length $(\mathbf{c m})$ & 7.93 & 5.27 & 6.30 & 7.30 & 6.33 & 6.83 \\
\hline
\end{tabular}

\section{Fluent Software and Viscous Model}

ANSYS Fluent software was used to model air flow inside the proposed precutter nozzles. The initial inlet velocity of $15.85 \mathrm{~m} / \mathrm{s}(52 \mathrm{ft} / \mathrm{s})$ was chosen based on the specifications given by the National Council for Air and Stream Improvement (NCASI) for a typical flow rate in emission stacks for paper mills (NCASI, personal communication). Model inputs corresponded to the physical properties of air at standard temperature and pressure.

An appropriate viscous model, within the ANSYS Fluent software, had to be chosen to properly model the effect of turbulence on air flow. The 2-dimensional $k$ - $\omega$ model was chosen as the viscous model, because it has the advantage of modeling a flow's near-wall interactions, which yields the ability to model inverse flow (Menter, 1994). As the accuracy of modeling nearwall interactions was very important to accurately model turbulence from the changes in crosssectional area, the 2-dimensional $k$ - $\omega$ model was the most applicable viscous model for this research (ANSYS, 2006). Mesh size, which determines grid size, is important in determining computational accuracy and dictating computational cost, needs to be optimized to balance the two factors. The geometry of each model was modeled at a meshing number of 5 million, which was determined to be the optimal number by comparing the results with varying meshing numbers from 1 million to 10 million. At this meshing number, each simulation took an average of 2 hours on an Intel Core i7-6700 processor at $2.40 \mathrm{GHz}$.

\section{Particle Trajectories by Discrete Phase Model}

Once the air flow inside a proposed precutter nozzle was fully modeled, PM was added to the flow field to observe and track how particles would behave in the nozzle. Spherical particles with a density of $1 \mathrm{~g} / \mathrm{cm}^{3}$ and a diameter between 2 and $16 \mu \mathrm{m}$ were injected into the nozzle, which is the particle size range of interest to this research. While the flow field for air in the nozzle was modeled using transport equations in the continuous phase, particle trajectories were simulated in a discrete second phase in a Lagrangian frame. Fluent computed the trajectories of these discrete 
phase entities to predict the effects of turbulence on the dispersion of particles present in the continuum phase (air flow) (ANSYS, 2001).

Injected particles were tracked to observe whether they were predicted to leave from the nozzle's outlet. If a particle did not leave the nozzle's outlet, the particle was considered collected. Collection efficiencies of the particles were calculated by the number of particles collected at a specific diameter divided by the total number of particles injected of that diameter. The collection efficiencies for proposed designs were then graphed to determine a design's cut size, which is the diameter at which $50 \%$ of the particles were collected.

The equations that Fluent used for these models are not presented here, as this research did not focus on the accuracy of different models provided by Fluent. Instead, a summary of the models used for this research was given to provide background information on how results were found.

\section{Results and Discussion}

From the particle trajectories of each simulation, the collection efficiencies and cut sizes of each design could be directly compared (see Figure 3 and Table 3). The differences in collection efficiencies can be explained by the differences in decreased flow speed at an impactor compared to a nozzle's inlet, which are determined by the half-cone angle and throat length. Once air flow reaches the impactor, the flow will change direction to proceed to the nozzle's outlet (see Figure 1). Relatively smaller particles will change direction in response to change in direction in air flow. However, an increase in particle size yields a larger inertia, increasing the likelihood that the particle does not change direction and instead continues its trajectory to be collected by the impactor. The increase in momentum as particle size increases explains the general trend of an increase in collection efficiency as particle size increases (see Figure 3). The rate at which a design's collection efficiency transfers from a particle diameter in which little to no particles are collected to a particle diameter in which all particles are collected (a diameter of $16 \mu \mathrm{m}$ for all designs) can be explained by a design's cut size (see Table 3). Based on specifications from NCASI and EPA regulators, the optimal target cut size was $12 \mu \mathrm{m}$. A smaller cut size would collect too many particles of interest to properly measure $\mathrm{PM}_{2.5}$, while a larger cut size would not properly collect enough of the larger particles to accurately measure PM. 


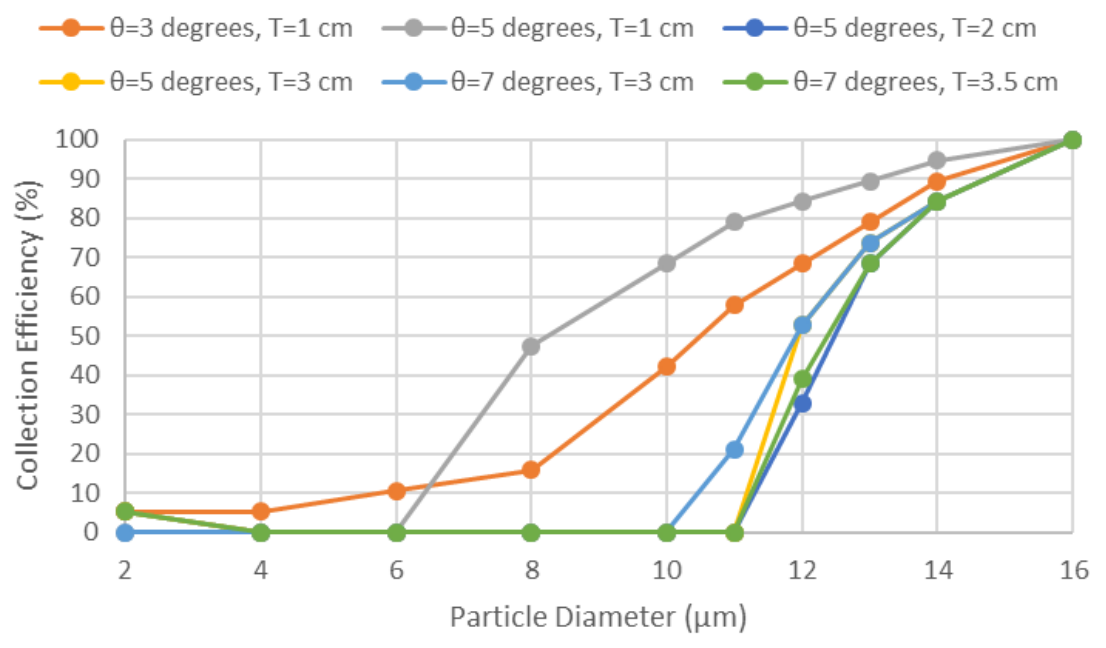

Figure 3: Collection efficiencies of potential nozzle designs.

Table 3: Approximate cut sizes of each nozzle design.

\begin{tabular}{|c|c|c|c|c|c|c|}
\hline Half-Cone Angle $\left(^{\circ}\right)$ & 3 & 5 & 5 & 5 & 7 & 7 \\
\hline Throat Length $(\mathrm{cm})$ & 1 & 1 & 2 & 3 & 3 & 3.5 \\
\hline Cut Size $(\mu \mathrm{m})$ & 10.5 & 8.3 & 12.5 & 11.9 & 11.9 & 12.3 \\
\hline
\end{tabular}

The closest designs to a cut size of $12 \mu \mathrm{m}$ were with the following throat lengths and halfcone angles, respectively: $3 \mathrm{~cm}$ and $5^{\circ}, 3 \mathrm{~cm}$ and $7^{\circ}$, and $3.5 \mathrm{~cm}$ and $7^{\circ}$. Therefore, the potential for inverse air flow, which is illustrated by a negative axial velocity, was further examined for these three designs (see Figures 4 through 7). As flow moved further from the inlet, the effect of inverse flow was dissipated. If there was no potential inverse flow detected at the throat outlet, which was the point of interest as it is the location right before a particle would hit the impactor, a design would be viable based on the criteria for no inverse flow at the impactor.

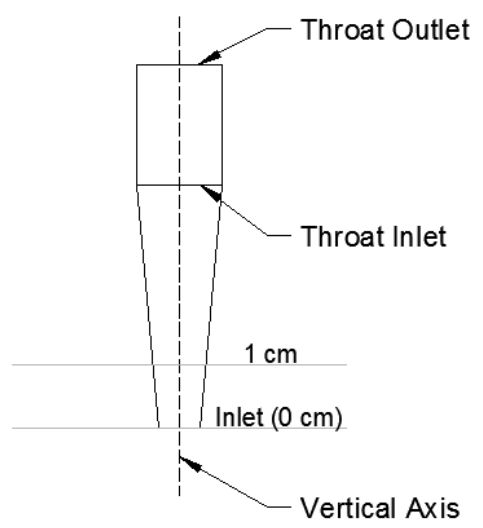

Figure 4: Configuration of where air flow velocity was observed relative to the inlet and vertical axis. 


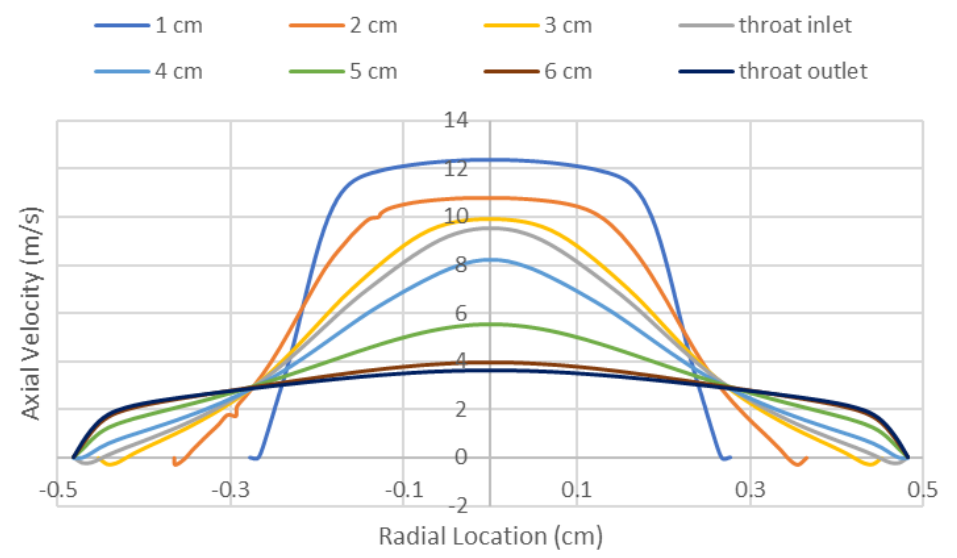

Figure 5: The axial velocity profile compared to the distance from the inlet and radial location with respect to the vertical axis (3-cm throat length and $5^{\circ}$ half-cone angle).

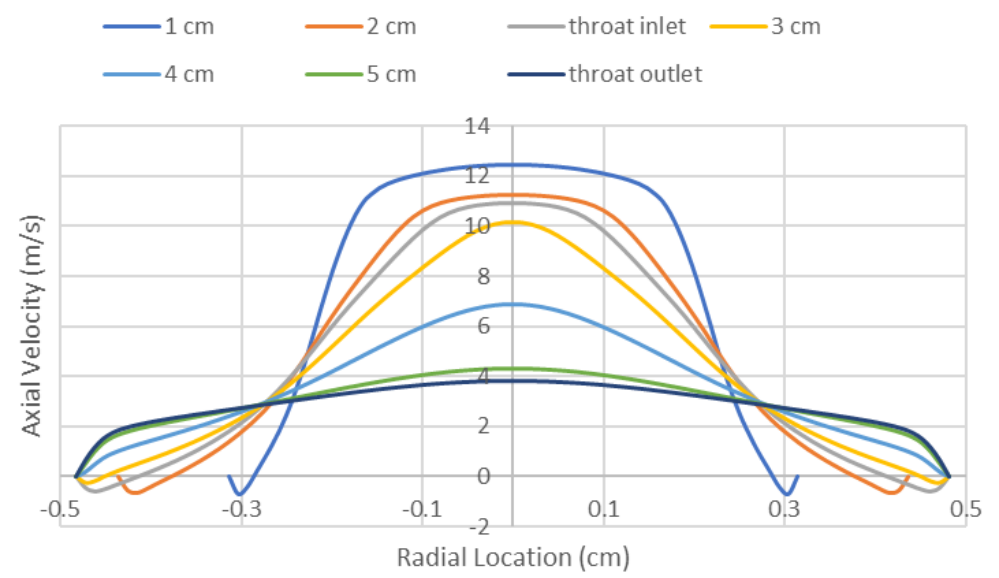

Figure 6: The axial velocity profile compared to the distance from the inlet and radial location with respect to the vertical axis (3-cm throat length and $7^{\circ}$ half-cone angle).

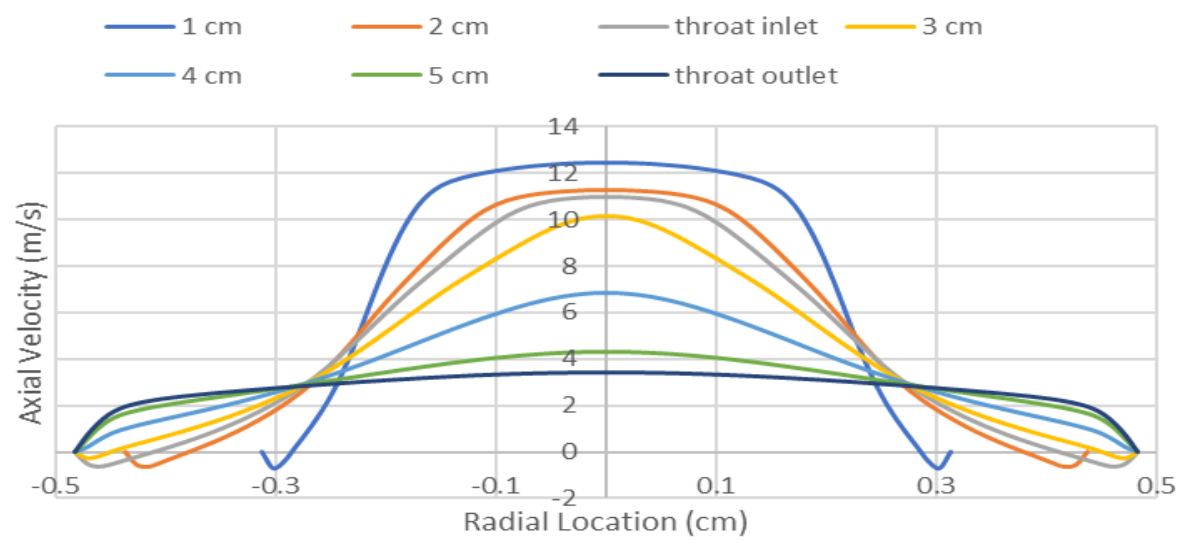

Figure 7: The axial velocity profile compared to the distance from the inlet and radial location with respect to the vertical axis (3.5-cm throat length and $7^{\circ}$ half-cone angle). 
For all three configurations - a throat length and half-cone angle of $3 \mathrm{~cm}$ and $5^{\circ}, 3 \mathrm{~cm}$ and $7^{\circ}$, and $3.5 \mathrm{~cm}$ and $7^{\circ}-$ no inverse flow was measured at the throat outlet (See Figures 5 through 7). Therefore, all three configurations met the study's design goals. According to the specifications of NCASI, smaller designs are favorable to use within a source's sampling inlet. As a result, a configuration with a half-cone angle of $7^{\circ}$ and a throat length of $3 \mathrm{~cm}$ is the most viable design at a total length of $6.33 \mathrm{~cm}$.

\section{Conclusions}

The current precutter nozzle of EPA OTM 36 collects more particles than intended, yielding underestimated $\mathrm{PM}_{2.5}$ concentrations to be collected by the downstream sampling train. The objective of this research was to design a precutter nozzle to accurately capture PM to improve the overall sampling train of OTM 36. To design a better precutter nozzle, the proposed design had to collect PM to a targeted cut size of $12 \mu \mathrm{m}$, prevent potential inverse flow within the nozzle, and be small enough to fit within a typical stack's sampling inlet. Based on these criteria, the most viable designs are with the following throat lengths and half-cone angles, respectively: $3 \mathrm{~cm}$ and $5^{\circ}, 3 \mathrm{~cm}$ and $7^{\circ}$, and $3.5 \mathrm{~cm}$ and $7^{\circ}$. With the shortest overall length of $6.33 \mathrm{~cm}$, the design with a throat length of $3 \mathrm{~cm}$ and half-cone angle of $7^{\circ}$ was concluded to be the most viable design. If this design is implemented, the sampling train of OTM 36 can more accurately measure $\mathrm{PM}_{2.5}$ concentration in emission sources, increasing the ability of the EPA to regulate $\mathrm{PM}_{2.5}$ emissions of different industries. Future research can focus on building a prototype of the proposed nozzle design to measure experimental collection efficiencies to compare to the computationally simulated results of this research.

\section{Acknowledgements}

This research was conducted as part of the University of Florida's University Scholars Program under the supervision and support of Dr. Chang-Yu Wu and Chih-Hsiang Chien in the Environmental Engineering and Sciences Department. Funding was provided by the National Council for Air and Stream Improvement. 


\section{References}

ANSYS. (2001). Chapter 19. Discrete Phase Models. ANSYS.

ANSYS. (2006). Modeling Turbulent Flows. Fluent User Services Center.

Garnett, K. (2015). PM Fine Wet Stack Method Development. EPA Measurement Technology Workshop.

General Compliance Test Requirements, 40 C.F.R. § 297 (1998).

John, A., Kuhlbusch, T., Fissan, H., Broker, G., \& Geueke, J. (2003). Development of a PM 10/PM 2.5 Cascade Impactor. Aerosol Science and Technology, 694-695. doi: $10.1080 / 02786820390199213$

Liu, B. Y. H., Zhang, Z. Q., \& Kuehn, T. H. (1989). A numerical study of inertial errors in anisokinetic sampling. Journal of Aerosol Science, 20(3), 367-380.

Measurement Technology Group. (2016). Other Test Method - 36: Method for the Determination of Filterable PM2.5 Emissions from Moisture. Research Triangle Park: Office of Air Quality Planning and Standards.

Menter, F. (1994). Two-Equation Eddy-Viscosity Turbulence Models for Engineering Applications. American Institute of Aeronautics and Astronautics.

Method 5 - Determination of Particulate Emissions from Stationary Sources, 40 C.F.R. $§ 60$ Appendix A (1991)

Murdock, J. (1993). Fundamental Fluid Mechanics for the Practicing Engineer (Mechanical Engineering). (L. Faulkner, Ed.) Boca Raton, FL, USA: CRC Press.

Williamson, A. D., Farthing, W. E., Ward, T. E., \& Midgett, M. R. (1987). Effects of sampling nozzles on the particle-collection characteristics of inertial sizing devices. Final report. Birmingham: Southern Research Institute. 